\title{
Multistage Deep Drawing with Ironing of Al-killed AISI 1040 Graded Medium Carbon Steel: a Parametric Study
}

\author{
Anil Kumar Parida ${ }^{a, b}$, Shatrughan Soren ${ }^{b *}$, Raghu Nandan Jha ${ }^{a}$, Nelepu Krishnamurthy ${ }^{c}$ \\ ${ }^{a}$ Metal and Steel Factory, Ishapore, 743144, India \\ ${ }^{b}$ Indian Institute of Technology (Indian School of Mines), Dhanbad, 826004, India \\ ${ }^{c}$ Controllerate of Quality Assurance (Metals), Ishapore, 743144, India
}

Received: August 08, 2016; Revised: March 31, 2017; Accepted: May 21, 2017

\begin{abstract}
Analysis of multistage deep drawing with ironing was made while manufacturing of cups from $12 \mathrm{~mm}$ thick, $60 \mathrm{~mm}$ diameter circular blanks of Al-killed AISI 1040 graded medium carbon steel. Quality requirements of the steel in heat treated condition were examined in terms of tensile properties, formability characteristics, and formability limit diagram. Drawability and ironability parameters in multistage cup drawing processes were evaluated in terms of draw ratio; draw reduction; ironing ratio; ironing reduction and thus its press formability in an actual state of practice was shown. Further, were analysed the influences of process parameters such as: semi die angle; interfacial friction coefficient; die-punch clearance on draw and ironing punch forces in each draw stage. The spring back tendency of cups in terms of their trends and degrees with respect to cup heights and draw stages were experimentally determined by conducting split ring test. Thus, a data bank was created as potential references for process engineers to improve the manufacturing process and draw tools as well, particularly for the selected steel.
\end{abstract}

Keywords: Medium carbon steel, Formability, Multistage deep drawing, Wall ironing, Process parameters, Spring back behaviour

\section{Introduction}

Steel cylindrical cups are widely used in automobile sectors, defence applications and other industries. While demand of these cups increases rapidly, the process optimization in manufacturing practice still needs more development in order to reduce lead-time, improve productivity and ensure product quality. Such products are manufactured by multi-stage deep drawing, which is sometimes accompanied with wall ironing technique for achieving uniform wall thickness and increased cup length. Since these processes are involved with a complicated deformation mechanism, the final mechanical properties are difficult to predict and also process design is not easy for manufacturing cups successfully with the desired shape and properties. Success or failure of metal forming by deep drawing accompanied with wall ironing is influenced by various process parameters such as: degrees and ratios of drawing as well as ironing; die entry semiangle; die-punch clearance; interfacial friction coefficient; inherent material properties like strength, strain hardening exponent, formability and so forth.

Because of the importance of deep drawing as well as ironing, the process (either by separately or in a combination) is being the subject of many experimental and theoretical investigations ${ }^{1-15}$. Many of these investigations have dealt with low strength metals with high formability, like: different grades of low carbon steels and aluminium alloys etc. To the best knowledge of authors', a study on effects of process parameters in manufacturing of cups from high strength metals is less attended, while medium carbon steel processed by multistage deep drawing accompanied with ironing method is found rarely available. Further, an application of $12 \mathrm{~mm}$ thick circular blanks for drawing long cylindrical cup is seen almost nonexistent. Such lack of information possibly arise a need of this investigation work to fill up the knowledge gap and create a databank as potential reference for process engineers to optimize manufacturing processes in deep drawing, automobile and defence industries.

The present paper is describing inherent material properties of aluminium (Al) -killed AISI 1040 graded medium carbon steel and thus input quality requirements are indicated for cup manufacturing from $12 \mathrm{~mm}$ thick circular blanks of $60 \mathrm{~mm}$ diameter. The degree of press formability of the steel while applied in a 3-stage deep drawing and ironing processes were evaluated in terms of Drawability and Ironability parameters. The effects of process parameters such as: semi die angle $(\alpha)$, interfacial friction coefficient $(\mu)$, and die-punch clearance (c) were analyzed by varying them and thus influences on punch forces were identified. Also, by split ring test, spring 
back behaviour of cups was determined for tool optimization, a future scope of work.

\section{Material and Methods}

\subsection{Material}

The chemical composition of the as received Al -killed AISI 1040 graded medium carbon steel is reported in Table 1. The basic input material as $15 \%$ cold reduced $14 \mathrm{~mm}$ thick strips were used for cup drawing after subjecting to a heat treatment cycle consisted with hardening (heating at $1133^{\circ} \mathrm{K}$ for 1 hour and water quenching) followed by a prolonged tempering (heating at $923^{\circ} \mathrm{K}$ for 36 hours, followed by furnace cooling to $472^{\circ} \mathrm{K}$ and air cooling to the room temperature).

\subsection{Mechanical properties and formability parameters evaluation}

Intrinsic mechanical properties of the steel in heat treated condition were determined by tensile test at ambient temperature $\left(298^{\circ} \mathrm{K}\right)$ on flat specimens $(5 \mathrm{~mm}$ thickness, $6.5 \mathrm{~mm}$ width and $32 \mathrm{~mm}$ gauge length) along $0^{\circ}, 45^{\circ}$, and $90^{\circ}$ to the rolling direction (RD), by using a $20 \mathrm{kN}$, KIL make (model PC 2000) electronic tensometer, at a strain rate $2.5 \times 10^{-4} \mathrm{~s}^{-1}$, according to standard IS 1608: $2005^{16}$. True values of tensile properties, yield strength $(Y S)$; tensile strength (UTS); yield ratio (YR); uniform elongation (UEl.); total elongation $(T E l$.) were determined from load-extension curves. The strain hardening exponent $(n)$, an indicator of formability, was evaluated by regression method, applying on tensile flow curves. The uniaxial formability parameters such as: normal anisotropy $\left(r_{\mathrm{m}}\right)$ and planar anisotropy $(\Delta r)$ values were evaluated by conducting tensile tests up to an elongation just 2-3\% below uniform elongation and using the following equations as per standard IS 11999: $2007^{17}$.

$$
r=\varepsilon_{\mathrm{w}} / \varepsilon_{t}=\ln \left(w_{0} / w\right) / \ln \left(t_{0} / t\right)
$$

Where, $r=$ plastic stain ratio; $\varepsilon_{\mathrm{w}}=$ plastic strain along width; $\varepsilon_{\mathrm{t}}=$ plastic strain along thickness; $w_{0}, t_{0}=$ width, thickness respectively of the specimen before test; $w, t=$ width, thickness respectively after test.

Then $r_{\mathrm{m}}$ and $\Delta r$-values were calculated using standard formulae ${ }^{17}$ as follows:

$$
\begin{gathered}
r_{m}=\left(r_{0}+2 r_{45}+r_{90}\right) / 4 \\
\Delta r=\left(r_{0}+r_{90}-2 r_{45}\right) / 2
\end{gathered}
$$

Where, the subscripts, $0^{\circ}, 45^{\circ}$ and $90^{\circ}$ are orientations to the RD of the steel strips.
The formability limit curve $(F L C)$ was determined by conducting Erichsen cup test at ambient temperature $\left(298^{\circ} \mathrm{K}\right)$, as per Indian standard IS 10175(Part 1): $1993^{18}$, by an electro-hydraulic drive Erichsen sheet metal testing machine (Model-140, drawing force 0-30 kN, sheet holding force 0-34 $\mathrm{kN}$ ), assembled with die-punch arrangements (Figure 1a). The test was done on $2 \mathrm{~mm}$ thick steel specimens of varying widths, $75 \mathrm{~mm}, 56 \mathrm{~mm}, 38 \mathrm{~mm}, 21 \mathrm{~mm}$ and $15 \mathrm{~mm}$, which were printed with $2.5 \mathrm{~mm}$ square grids (equivalent to grid circles of $2.5 \mathrm{~mm}$ diameter). More importantly, these $2 \mathrm{~mm}$ thick specimens were cut from the steel strips by using CNC Wire-cut EDM machine, followed by grind finish. Proper precautions were taken during sample preparation to maintain intact condition of the inherent material properties. In order to obtain maximum values in the magnitude of negative minor strains, uniaxial tension tests were also done using grid-marked specimens. These tests were conducted up to failure or to localized necking in some cases.
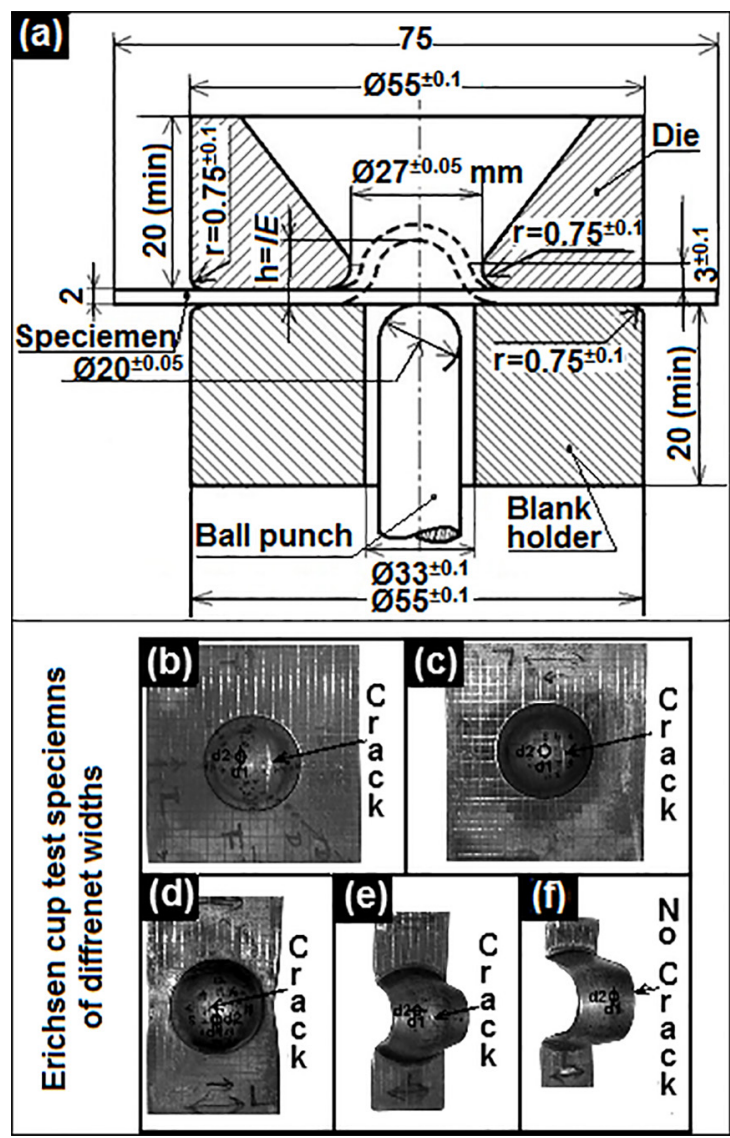

Figure 1. (a) Schematic showing of Erichsen cup test arrangements; (b-f) photo images of Erichsen cup specimens of different widths.

Table 1. Chemical composition of Al-killed AISI 1040 steel (in \% wt.).

\begin{tabular}{ccccccccccccccc}
\hline Elements & $\mathrm{C}$ & $\mathrm{Mn}$ & $\mathrm{Si}$ & $\mathrm{S}$ & $\mathrm{P}$ & $\mathrm{Ni}$ & $\mathrm{Cr}$ & $\mathrm{Mo}$ & $\mathrm{Al}$ & $\mathrm{Cu}$ & $\mathrm{Sn}$ & $\mathrm{As}$ & $\mathrm{Sb}$ & $\mathrm{Fe}$ \\
\hline $\mathrm{wt}^{2} \%$ & 0.39 & 0.79 & 0.34 & 0.009 & 0.005 & 0.12 & 0.18 & 0.10 & 0.05 & 0.08 & 0.0059 & 0.0053 & 0.0018 & $\mathrm{Bal}$. \\
\hline
\end{tabular}

Note: $\mathrm{H}, \mathrm{O}$ and $\mathrm{N}$ are 1.8, 18.4 and 82.3 ppm respectively; Bal. = balance quantity. 
True major $\left(\varepsilon_{1}\right)$ and minor $\left(\varepsilon_{2}\right)$ strains were calculated from measurements of deformed grids ${ }^{19-21}$ on specimens after testing (Figures 1b-f) and were expressed in a 2D strain space, known as formability limit diagram $(F L D)^{22}$. A line was drawn just below the points under visible necking as well as of the fracture zone, known as formability limit curve (FLC).

\subsection{Multistage cup drawing}

Cup drawing experiment were conducted by multistage (three stages) deep drawing with simultaneous ironing processes on high speed mechanical press machines, without using blank holders, considering relatively thicker blanks ${ }^{23}$. The processing steps which were followed during the experiment such as: blanking for forming of circular blanks - facing of blanks at both sides - stress relieving, surface treatment and lubrication - stamping for pre-forming of blanks - stress relieving, surface treatment and lubrication - 1st draw - stress relieving, surface treatment and lubrication - 2nd draw - stress relieving, surface treatment and lubrication - 3rd as final draw - stress relieving treatment. After each step of press work, the components were stress relieved with a heating cycle, $933-983^{\circ} \mathrm{K}$ for 4 hours - furnace cooling to $473^{\circ} \mathrm{K}$ - air cooling to room temperature, to eliminate strain hardening effect ${ }^{24}$. On completion of stress reliving, components were undergone an intermediate surface treatment by acid pickling (HCl: 6-7\%, PH: 2-5) for removal of oxide coating; phosphating for ensuring a 5-10 $\mu \mathrm{m}$ thick porous layer to enhance lubricant carrying ability of the surface during press work; lubricating by immersing in soap solution (33\% soap flakes) for 2 hours in order to ensure a complete diffusion of the solution into the pores of phosphate coating layer.

Circular flat blanks of $60 \mathrm{~mm}$ diameter were cut from $14 \mathrm{~mm}$ thick heat treated strips by blanking operation on a 500 tons high speed mechanical press with blanking tools, schematically shown in Figure 2a. Blanks thus produced (Figure 2c) were undergone surface machining (facing) at both sides up to $12 \mathrm{~mm}$ thick, in order to discard the decarburized surface layer generated during heat treatment. Before taking into cupping process, these circular flat blanks were undergone to a stamping operation, schematically shown in Figure $2 b$, on a 250 tons mechanical press to give a preformed shape (little draw-in shape with a concave radius, R13), shown in Figure 2d. The preformed blanks (Figure 2d) were then subjected to 3 -stage cup drawing experiment by using high speed mechanical press machines of 500 tons in the first draw, 350 tons in the second draw and 250 tons in the third draw. Figures 3a-c show the schematic arrangements of the stage wise tooling, Table 2 illustrates all involved process parameters, and Figures 3d-f exhibit the photo images of cups drawn in each draw step.

The dimensions of drawn cups were measured by digital micrometers and vernier callipers after sectioning the cups at

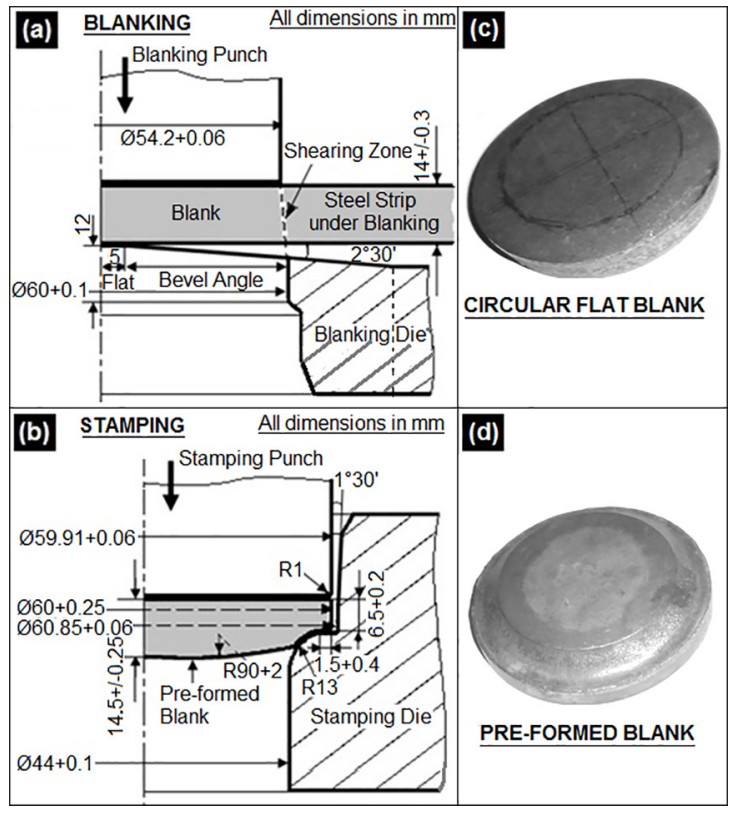

Figure 2. Schematically showing of arrangements, (a) blanking, and (c) stamping; Photo images, (b) circular flat blank, and (d) preformed blank.

middle portion. Based on dimension of components and draw tools used in a stage, Drawability and Ironability parameters were evaluated for the respective draw stage by using few standard formulae obtained from different literatures.

The effects of different process parameters such as: semi die angle $(\alpha)$, interfacial friction coefficient $(\mu)$, and diepunch clearance $(c)$ on particularly on punch forces (draw and ironing punch forces) in each draw stage were analyzed based on standard force equations found from literatures.

Further, the spring back tendency of the drawn cups along their walls in each draw stage were determined by a simple and repeatable Demeri split ring test. The test was conducted, as described by Foecke and Herold ${ }^{25}$; Danckert ${ }^{26}$, on ring specimens ( $7 \mathrm{~mm}$ wide) cut from the drawn cups, at different heights and then were mechanically slitted longitudinally along their radial planes, schematically shown in Figure 4. Thus resulted gaps of splitted rings were evaluated by measuring differences between ring diameters, i.e. before and after splitting and expressed as the spring back tendency of the drawn cup walls.

\section{Results and Discussions}

\subsection{Mechanical properties and formability}

Table 3 describes mechanical properties and formability parameters of steel strips in heat treated condition. It shows its average $U T S \sim 634 \mathrm{MPa} ; U E l \sim 23 \%$; TEl $\sim 38 \%$, indicate a good combination of strength-ductility. The average $\mathrm{n}$-value, 0.42 , signifies its high strechability with uniform strain 


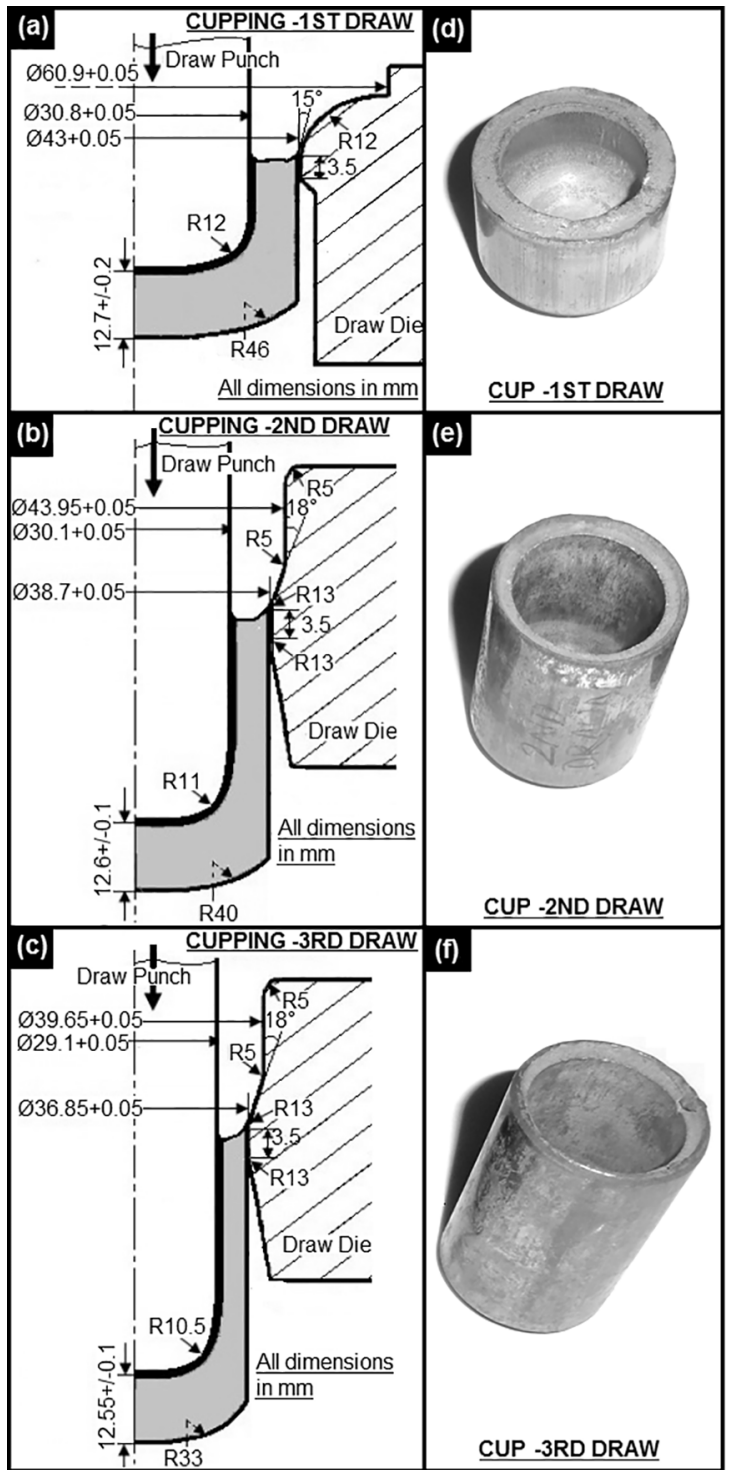

Figure 3. 3-stage cup drawing, (a-c) schematically showing of arrangements; (d-f) photo images of drawn cups.

dispersibility ${ }^{19,27-29}$. The uniaxial formability characteristics evaluation shows its $r_{\mathrm{m}}$-value, $1.1(>1)$, and $\Delta r$-value, 0.18 , imply that the steel has moderate drawability with good earing resistance.

The FLD is graphically represented in Figure 5 wherein the true $F L C$ distinguishes a safe forming zone of the steel under investigation. The lowest forming limit has been observed at plain strain condition $\left(\varepsilon_{2}=0\right){ }^{19}$, showing the true $F L C_{0}=33.451 \%$, which is significant.

\subsection{Drawability and ironability (press formability)}

Table 4 summarizes cup dimensions obtained in 3-stage cup drawing experiment. By using these data in Equations $4-11^{2,11,30,31}$, various drawability and ironability parameters were evaluated for each draw step.
Draw ratio $(\beta)=D_{\mathrm{i}} / D_{\mathrm{P}-\mathrm{i}}$

Overall draw ratio $\left(\beta_{o}\right)$, i.e.

limiting draw ratio $(L D R)=D_{0} / D_{\mathrm{P}-\mathrm{f}}$

Draw reduction $\left(r_{d}\right), \%=$

$\left[\left(D_{\mathrm{i}-1}-D_{\mathrm{P}-\mathrm{i}}\right) / D_{\mathrm{i}-1}\right] \times 100$

Overall draw reduction $\left(r_{\mathrm{d}-o}\right) \%=$

$\left[\left(D_{0}-D_{\mathrm{P}-\mathrm{f}}\right) / D_{0}\right] \times 100$

Ironing ratio $(I R)=T_{\mathrm{i}-1} / T_{\mathrm{i}}$

Overall ironing ratio $\left(I R_{o}\right)$, i.e.

limit ironing ratio $(L I R)=T_{0} / T_{\mathrm{f}}$

Ironing reduction $\left(r_{\mathrm{i}}\right), \%=$

$\left[\left(T_{\mathrm{i}-1}-T_{\mathrm{i}}\right) / T_{\mathrm{i}-1}\right] \times 100$

Overall ironing reduction $\left(r_{\mathrm{i}_{-}}\right) \%=$

$\left[\left(T_{0}-T_{\mathrm{f}}\right) / T_{0}\right] \times 100$

Where, $D_{0}=$ diameter of the blank (before cupping); $D_{\mathrm{i}}$, $D_{\mathrm{i}-1}=$ outer diameter of the cup after and before the stage -(i) respectively; $D_{\text {P-i }}, D_{\text {P-f }}=$ diameter of punch in the stage -(i) and the final stage respectively; $T_{0}=$ thickness of the blank (before cupping); $T_{\mathrm{i}}, T_{\mathrm{i}-1}$ and $T_{\mathrm{f}}=$ thickness of cup wall in the stage -(i), -(i-1), and the final stage respectively.

Table 4 also depicts values of drawability and ironability parameters under which the cups are drawn. It shows the maximum values of ratios, $\beta$ and $I R$, in the first draw stage and their decreasing trend is observed in subsequent stages. The stage wise variation of reduction parameters $\left(r_{\mathrm{d}}, r_{\mathrm{i}}\right)$, demonstrates a similar trend as found for ratios. This tendency is as expected from the process design, ensuring uniform distribution of deformation among three different draw steps. Considering the overall draw steps, the calculation shows the $L D R$ value, 2.06 ; the $L I R$ value, 3.55 ; the overall draw reduction $\left(r_{\mathrm{d}-\mathrm{o}}\right), 51.5 \%$ and the overall ironing reduction $\left(r_{\mathrm{i}-\mathrm{o}}\right), 71.85 \%$, which confirm good press formability of the steel in actual state of application.

\subsection{Influence of various process parameters on punch forces}

Effects of different process parameters, such as: semi die angle $(\alpha)$; interfacial friction coefficient $(\mu)$; die-punch clearance $(c)$, on draw and ironing punch forces were analyzed by varying their values separately and applying in the draw and ironing punch force equations, while the other parameters kept constant. The following standard punch force equations were obtained from different related 
Table 2. Equipments, tools and process parameters used in 3-stage cup drawing operations.
(a) Equipments/tools
(b) Technical details/process parameters

First draw: Capacity- 500 Tons, crank type mechanical press of single action, stroke length- $200 \mathrm{~mm}$, and ram speed- $83 \mathrm{~mm} \cdot \mathrm{s}^{-1}$.

A Press machine

Second draw: Capacity- 350 Tons, crank type mechanical press of single action, stroke length- $610 \mathrm{~mm}$, and ram speed- $183 \mathrm{~mm} \cdot \mathrm{s}^{-1}$.

Third draw: Capacity- 250 Tons, crank type mechanical press of single action, stroke length- $640 \mathrm{~mm}$, and ram speed- $192 \mathrm{~mm} \cdot \mathrm{s}^{-1}$.

Die Profile: schematically shown in Figs. 3(a), (b) and (c) for first, second and third draw stages respectively.

B Draw die Surface finish: grind finish with polished surface at the effective working zones.

Die material: IS: T108/ JIS: SK 3, 4 steel.

Die hardness: 578-652 BHN on hardened and tempered condition.

Punch profile: schematically shown in Figs. 3(a), (b) and (c) for first, second and third draw stages respectively.

C Cupping punch Surface finish: grind finish with polished surface at the effective working zones.

Punch material: IS: T108/ JIS: SK 3, 4 steel.

Punch hardness: 578-652 BHN on hardened and tempered condition.

First draw: $31.8+0.06 \mathrm{~mm}$ (min.) diameter.

Second draw: $31.2+0.06 \mathrm{~mm}$ (min.) diameter.

D Stripper (three parts segmented type)

Third draw: $30.5+0.06 \mathrm{~mm}$ (min.) diameter.

(Stripers are fitted at the exit end of draw dies, with peripheral spring tension for extraction of the drawn cups after each stage of drawing).

First draw: $6.00+0.10 \mathrm{~mm}$.

E Die-punch clearance Second draw: $4.20+0.10 \mathrm{~mm}$

Third draw: $3.80+0.10 \mathrm{~mm}$.

F Lubricant

Water diluted soap flakes [33\% Sodium oleostearate, technical (soap noodles) as per IS 10513-1983, Table 1 , clauses $4.4,8.1$ and 8.3 , type- 1 and $\left.67 \% \mathrm{H}_{2} \mathrm{O}\right]$.

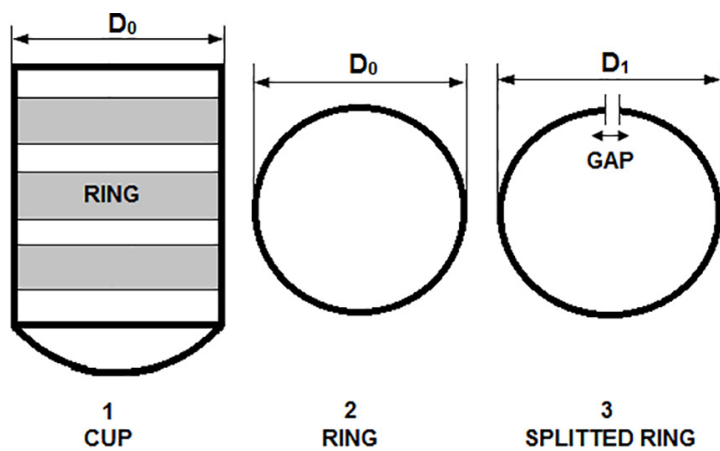

Figure 4. Schematically showing of split ring test schedules.

literatures, wherein assumed a plain strain condition, because of circumference of the cup wall was constrained by the rigid punch from shrinkage and thus yielded of a negligible $(\approx 0)$ circumferential strain.
The draw punch force in first draw stage was calculated by Equation 12, described by Boljanovic ${ }^{31}$.

$$
\begin{aligned}
& P_{\mathrm{D}-1}=\left[\left\{\pi D_{\mathrm{P}} t \cdot\left(1.1 k_{\mathrm{f}-\mathrm{m}}\right) \cdot \ln \left(D_{0} / D_{\mathrm{P}}\right)\right\} .\right. \\
& \exp \cdot(\mu \cdot \pi / 2)]+[B]
\end{aligned}
$$

Where, $D_{\mathrm{P}}=$ punch diameter, $D_{0}=$ blank diameter, $t=$ wall thickness, $k_{\mathrm{f}-\mathrm{m}}=$ average flow stress (MPa) $\mu=$ coefficient of friction at die radius and was assumed $\approx 0.16^{31}, B=$ force to bend and re-straighten the blank in cup forming.

The average flow stress, $k_{\mathrm{f}-\mathrm{m}}$ was calculated by using the Equation $13^{32}$ :

$$
k_{\mathrm{f}-\mathrm{m}}=\left(k_{\mathrm{f}-0}+k_{\mathrm{f}-1}\right) / 2
$$

Where, $k_{\mathrm{f}-0}=$ flow stress before forming (for $\varphi_{\mathrm{P}}=0$ ) i.e. yield stress of the material, $k_{\mathrm{f}-1}=$ flow stress at the end of forming (for $\varphi_{\mathrm{P}}=\varphi_{\max }$ ) and its value was evaluated by using

Table 3. Tensile properties and formability characteristics of Al-killed AISI 1040 steel strips in heat treated condition.

\begin{tabular}{lcccccccc}
\hline Orientation w.r.t. $\mathrm{RD}\left({ }^{\circ}\right)$ & $Y S(\mathrm{MPa})$ & $U T S(\mathrm{MPa})$ & $Y R(\%)$ & UEl.32 $(\%)$ & $T E l .(\%)$ & $n$-value & $r$-value & Hardness $(\mathrm{VH})$ \\
\hline 0 & 390.14 & 651.84 & 59.85 & 22.2 & 40.97 & 0.437 & 1.11 & \\
45 & 374.4 & 629.8 & 59.45 & 23.98 & 38.9 & 0.418 & 1.01 & \\
90 & 354.83 & 624.44 & 56.82 & 22.57 & 33.77 & 0.399 & 1.27 & 202 \\
Normal mean $\left(X_{m}\right)$ & 373.44 & $633.97 \approx 634$ & $58.89 \approx 59$ & $23.18 \approx 23.2$ & 38.13 & $0.418 \approx 0.42$ & 1.1 & \\
Planar mean $(\Delta X)$ & & & & & & & 0.18
\end{tabular}

Note: $X_{m}=\left(X_{0}+2 X_{45}+X_{90}\right) / 4 ; \Delta X=\left(X_{0}-2 X_{45}+X_{90}\right) / 2 ;$ UEl32, Uniform elongation in $32 \mathrm{~mm} ; r$-value measured at $16-17 \%$ of $U E l$; $n . r=$ Overall press performance factor. 


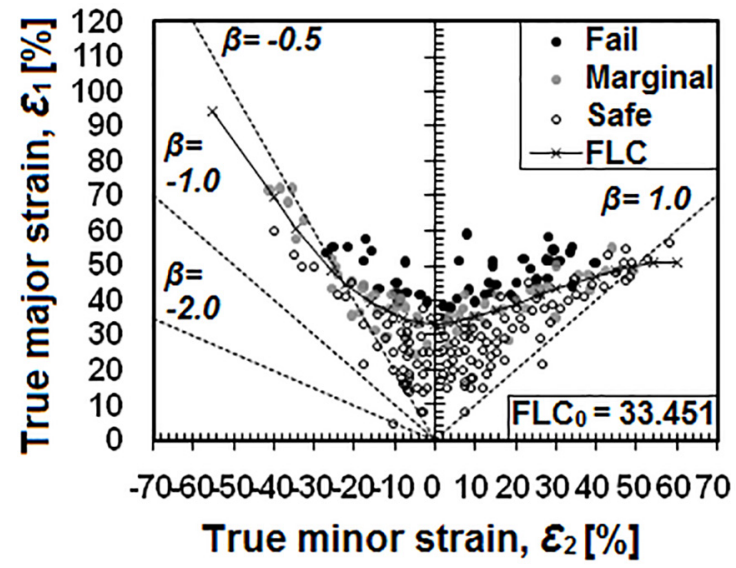

Figure 5. Graphical showing of $F L D$, plotted from Erichsen cup test.

the equation of flow stress curve, i.e $k_{\mathrm{f}}=C . \varphi_{\mathrm{P}}{ }^{n 32}$, where, $\varphi_{\mathrm{P}}$ $=$ principal strain, $C=$ strain hardening coefficient and $n$ $=$ strain hardening exponent.

The bend force, $B$, was calculated by using the Equation $14^{30}$ :

$$
\begin{aligned}
& B=\left[\left(k_{\mathrm{f}-\mathrm{m}} \cdot L \cdot t^{2}\right) / 2\left(R_{\mathrm{d}}+0.5 t\right)\right] \\
& \mathrm{x} \tan (\gamma / 2)
\end{aligned}
$$

Where, $L=$ total length to bend i.e. perimeter $\left(\pi D_{0}\right)$ of the preformed blank $=189.12 \mathrm{~mm}, t=$ thickness of the preformed blank (13 mm, the average measured thickness at the zone under bending action), $R_{\mathrm{d}}=$ bend radius i.e. die radius $(R 12)$, $\gamma=$ bend angle i.e. $90^{\circ}$ in the present investigation.

Draw punch forces in second and third draw stages were evaluated by Equation 15, described by Boljanovic ${ }^{31}$.

$$
\begin{aligned}
& P_{\mathrm{i}}=\left[\pi D_{\mathrm{P}-\mathrm{i}} t_{\mathrm{i}}\right] \times[1.1\{1+(\mu \pi 2 \alpha / 180)\} \times \mathrm{x} \\
& \left\{(1.21 / 1.44) k_{\mathrm{f}-\mathrm{m}}\right\} \times\{1+(\tan 2 \alpha / \mu)\} \times \\
& \left.\left\{1-\left(D_{\mathrm{m}-\mathrm{i}} / D_{\mathrm{m}-(\mathrm{i}-1)}\right)^{(\mu / \tan 2 \alpha)}\right\}\right]
\end{aligned}
$$

Where, $\mathrm{i}=$ draw stage no., $P_{\mathrm{i}}=$ punch force in $\mathrm{i}$-stage, $D_{\text {P-I }}=$ punch diameter in i -stage, $t_{\mathrm{i}}=$ cup wall thickness in $\mathrm{i}$-stage after drawing, $D_{\mathrm{m}-\mathrm{i}}=$ mean dia. of cup after drawing in i -stage, $D_{\mathrm{m} \text {-(i-1) }}=$ mean dia. of cup after drawing in (i-1) -stage, $\alpha=$ semi die angle in degree, $k_{\mathrm{f}-\mathrm{m}}=$ average flow stress in $\mathrm{MPa}$ (calculated by Equation 16 assuming $k_{\mathrm{f}-0}=$ yield stress of the material because of stress relieving treatment after drawing), $\mu=$ interfacial friction coefficient, assumed as $\sim 0.16^{31}$.

The ironing punch force in each draw step was evaluated by Equation 16, described by Folle et al. ${ }^{7}$.

$$
F=k_{\mathrm{f}-\mathrm{m}} A_{\mathrm{i} \varphi \mathrm{P}}\left[1+\mu / \alpha+2 \alpha / 3_{\varphi \mathrm{P}}\right]
$$

Where, $k_{\mathrm{f}-\mathrm{m}}=$ mean flow stress in $\mathrm{MPa}$ (Equation 13), $A_{\mathrm{i}}=$ cross-sectional area of the cup after ironing in i -stage, $\varphi_{\mathrm{P}}=$ principal strain, $\alpha=$ semi die angle in degree, $\mu=$ interfacial friction coefficient, assumed as $\sim 0.16^{31}$.

\subsubsection{Influence of process parameters $(\alpha, \mu, c)$ on draw punch forces}

Figure 6a shows influences of semi die angle $(\alpha)$; interfacial friction coefficient $(\mu)$; die-punch clearance $(c)$ on draw punch force in first draw stage, where trends of the force are plotted against varying values of $\alpha ; \mu ; c$ i.e. less than, equal to and greater than design values of the respective parameter. From figure, it is observed that the semi die angle has almost nil effect on force, which is as expected from the force equation used in the equation, considering non steady state of deformation in the stage. It is also seen that the draw force gets mounted on an escalation of both the interfacial friction coefficient and the die-punch clearance. Moreover, the friction coefficient is found to be the most influential factor among all.

Figures $6 \mathrm{~b}-\mathrm{c}$ represent the effect of the process parameters on draw punch forces in second and third draw stages respectively, wherein the semi die angle is found influencing inversely the force in both the stages unlike to the first stage. Herein both stages, the die-punch clearance is found as the largest influential parameter and the interfacial friction coefficient is next to it.

\subsubsection{Influence of process parameters $(\alpha, \mu, c)$ on ironing punch forces}

Figure 7a depicts the influence of the semi die angle $(\alpha)$ on ironing punch force in first draw stage with respect

Table 4. Drawability and Ironability obtained in 3-stage cup drawing processes.

\begin{tabular}{lccccccccc}
\hline & \multicolumn{4}{c}{ Punch and Cup size $(\mathrm{mm})$} & \multicolumn{2}{c}{ Drawability } & \multicolumn{2}{c}{ Ironability } \\
\hline Draw Stages & $\begin{array}{c}\text { Punch } \\
\text { Dia. }\left(D_{\mathrm{p}}\right)\end{array}$ & $\begin{array}{c}\text { Initial } \\
\text { Dia. }\left(D_{\mathrm{o}}\right)\end{array}$ & $\begin{array}{c}\text { Finish } \\
\text { Dia. }(D)\end{array}$ & $\begin{array}{c}\text { Initial } \\
\text { Thick. }\left(t_{\mathrm{o}}\right)\end{array}$ & $\begin{array}{c}\text { Finish } \\
\text { Thick. }(t)\end{array}$ & $\begin{array}{c}\text { Draw } \\
\text { Ratio }(\beta)\end{array}$ & $\begin{array}{c}\text { Drawing } \\
\text { Reduction } \\
\left(r_{\mathrm{d}}\right) \%\end{array}$ & $\begin{array}{c}\text { Ironing } \\
\text { Ratio }(I R)\end{array}$ & $\begin{array}{c}\text { Ironing } \\
\text { Reduction } \\
\left(r_{\mathrm{i}}\right) \%\end{array}$ \\
\hline $1^{\text {st }}$ draw & $30.8^{+0.05}$ & $60^{+0.25}$ & $43^{+0.06}$ & $13.5^{+0.5}$ & $6^{+0.1}$ & 1.95 & 48.67 & 2.25 & 55.55 \\
$2^{\text {nd }}$ draw & $30.1^{+0.05}$ & $43^{+0.06}$ & $38.7^{+0.06}$ & $6^{+0.1}$ & $4.2^{+0.1}$ & 1.28 & 22.22 & 1.43 & 30.00 \\
$3^{\text {rd draw }}$ & $29.1^{+0.05}$ & $38.7^{+0.06}$ & $36.85^{+0.06}$ & $4.2^{+0.1}$ & $3.8^{+0.1}$ & 1.26 & 21.03 & 1.10 & 09.52 \\
\hline \multirow{2}{*}{ Overall Stages } & & & & & & 2.06 & 51.50 & 3.55 & 71.85 \\
\hline
\end{tabular}

Note: $L D R=$ limit draw ratio, and $L I R=$ limit ironing ratio. 


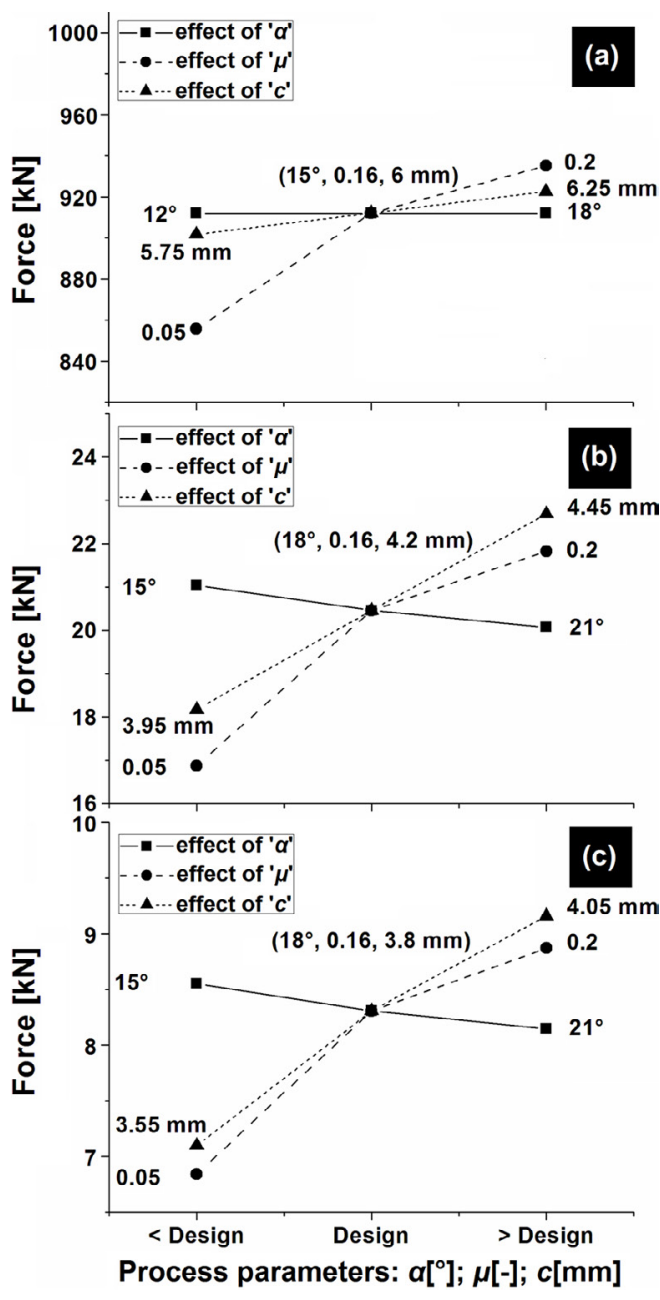

Figure 6. Graphical showing of influences of process parameters $(\alpha$; $\mu ; c$ ) on draw punch force, (a) $1^{\text {st }}$ draw, (b) $2^{\text {nd }} d r a w$, and (b) $3^{\text {rd }}$ draw. to thickness reduction during the process. Since at initial stage while the material entering the die, the cup thickness doesn't reduce instantly, therefore no strain is shown. As the material passes through the die, there is a sudden rise in the ironing force up to a value indicated in the figure. Herein the force is observed going up by increasing the value of ' $\alpha$ '.

Figures $7 b-c$ present the influence of semi die angle $(\alpha)$ on ironing forces in second and third draw stages respectively, with respect to thickness reductions in the stages. Herein both the stages, forces show a trend similar to the first draw stage, but at different degrees. Further, on advancement of the draw stages, levels of these forces are found reducing, attributed by decreasing values of the thickness reductions.

Figures 7d-f illustrate the effects of interfacial friction coefficient $(\mu)$ on ironing forces in first, second and third draw steps respectively. Herein, it is distinguished that the friction coefficient between the material and the die has not influenced the forces convincingly in all three stages, which perhaps due to the high values of forces have rendered comparatively very small deviations to the respective force lines and thus these lines have almost coincided with each other. Hence the process parameter, ' $\mu$ ' can be considered as of very little effect on the ironing force, although a reverse trend has been witnessed in case of the draw punch force is concerned, discussed in the earlier section.

Figures $7 \mathrm{~g}$-i demonstrate the effects of die-punch clearance (c) on the ironing forces in first, second and third draw stages respectively. Herein, it is observed that an increase in value of the parameter ' $c$ ' that makes the forces to rise up and also a reverse effect is observed while decreasing its value. Thus it confirms that if there is a misalignment between draw punch-die, there would be a significant imbalance in

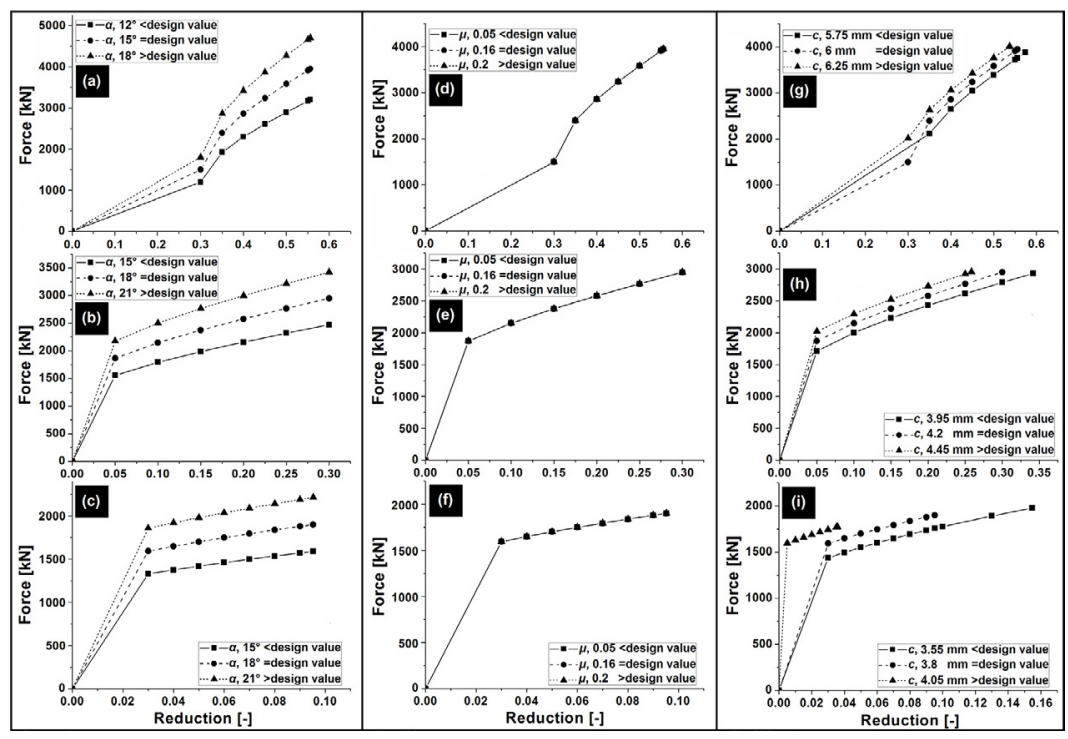

Figure 7. Graphical showing of ironing punch force influenced by, (a-c) semi die angle ( $\alpha$ ); (d-f) interfacial coefficient of friction $(\mu)$; $(\mathrm{g}-\mathrm{i})$ die-punch clearance $(c)$, in $1^{\text {st }} d r a w, 2^{\text {nd }}$ draw and $3^{\text {rd }}$ draw respectively in each case. 
the forces, which would cause to be consequent excessive wear on die-punches.

Figures 8a-c display the effects of these three process parameters $(\alpha, \mu, c)$, all together, on ironing forces in first, second and third draw stages respectively. An analysis of these figures reveals that the semi die angle $(\alpha)$ has influenced the forces with a maximum effect in all the draw stages, whereas the friction coefficient $(\mu)$ is with the least effect.

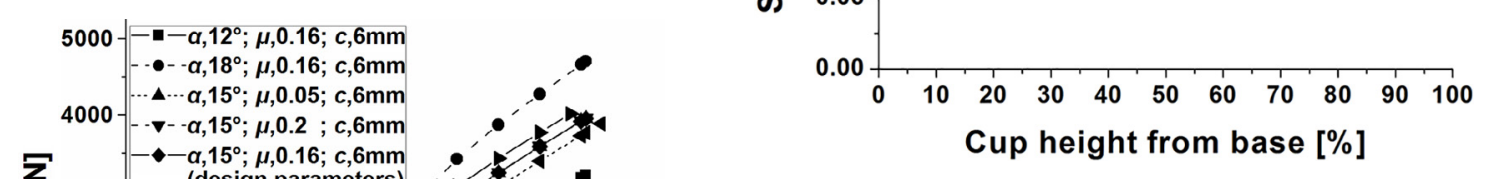

Figure 9. Schematically showing of spring back behaviour of cup walls in terms of split ring gaps $\left(1^{\text {st }}-2^{\text {nd }}-3^{\text {rd }} d r a w\right)$.

draw steps, which perhaps due to decrease in residual hoop stresses on cup walls, caused by increasing predominance of wall ironing ${ }^{26}$ in second and third draw steps.

\section{Conclusions}

- A typical heat treatment cycle i.e. hardening by water quenching followed with a long (36 hours) tempering at higher temperature $\left(923^{\circ} \mathrm{K}\right)$, applied on the selected medium carbon steel (Al-killed AISI 1040 grade) strips, has provided a good combination of strength-ductility-formability, which indicates its cup drawing applicability with moderate drawability and a maximum strength up to $\sim 634 \mathrm{MPa}$.

- The multistage deep drawing with simultaneous ironing process applied on $12 \mathrm{~mm}$ thick, $60 \mathrm{~mm}$ diameter circular steel blanks has shown a good press formability of the steel by rendering overall draw reduction, $51.5 \%$ with $L D R, 2.06$ and overall ironing reduction, $71.85 \%$ with $L I R, 3.55$, those have been achieved in the investigation held in three potential draw steps.

- Another important aspect observed was the influence of process parameters, such as: semi-die angle $(\alpha)$, interfacial friction coefficient $(\mu)$, and die-punch clearance $(c)$ on draw and ironing punch forces. Considering draw punch forces, the friction coefficient was observed to be the most influential factor in first draw stage and so was the die-punch clearance in second and third stages. In case of ironing punch forces, the die-punch clearance and the semi die angle showed immense effect on the forces in all three draw stages, while the semi die angle was the most influential one and the friction coefficient was proved to be less essential to the process. Further, effects of these three process parameters $(\alpha, \mu, c)$, all together had also shown a similar trend, where the semi die angle was the most influential factor and the friction coefficient was the least one. 
- $\quad$ For all three draw stages, the degree of spring back tendency of cups were found increasing with increasing cup heights from their bases, while they reduced on advancement of draw stages from first to third one.

- The databank created in the investigation can be gainfully exploited for further improvement in process optimization and tool designing in manufacturing of cups from the steel.

\section{Acknowledgements}

The steel was supplied by Metal \& Steel Factory, Ishapore, West Bengal, India and the experimental facilities were also extended by them. The authors gratefully acknowledge this.

\section{References}

1. Anaraki AP, Shahabizadeh M, Babaee B. Finite element simulation of multi-stage deep drawing processes \& comparison with experimental results. World Academy of Science, Engineering and Technology. 2012;61:670-674.

2. Jawad WK. Design modification in a multi-stage deep drawing process. Engineering \& Technology Journal. 2008;26(1):29-44.

3. Kim SH, Kim SH, Huh H. Tool design in a multi-stage drawing and ironing process of a rectangular cup with a large aspect ratio using finite element analysis. International Journal of Machine Tools and Manufacture. 2002;42(7):863-875.

4. Chang DF, Wang JE. Influence of process parameters on the ironing of deep-drawn cups. Journal of Manufacturing Science and Engineering. 1997;119(4B):699-705.

5. Gotoh M, Kim YS, Yamashita M. A fundamental study of can forming by the stretch-drawing process. Journal of Materials Processing Technology. 2003;138(1-3):545-550. DOI: 10.1016/ S0924-0136(03)00144-4

6. Rubio EM, González C, Marcos M, Sebastián MA. Energetic analysis of tube drawing processes with fixed plug by upper bound method. Journal of Materials Processing Technology. 2006;177(1-3):175-178. DOI: 10.1016/j.jmatprotec.2006.03.193

7. Folle LF, Netto SES, Schaeffer L. Analysis of the manufacturing process of beverage cans using aluminum alloy. Journal of Materials Processing Technology. 2008;205(1-3):347-352. DOI: $10.1016 /$ j.jmatprotec.2007.11.249

8. Courbon J. Damage evolution in a compressive forming process: ironing of beverage cans. Scripta Materialia. 2003;48(11):15191524. DOI: $10.1016 / \mathrm{S} 1359-6462(03) 00131-3$

9. Jain M, Allin J, Bull MJ. Deep drawing characteristics of automotive aluminum alloys. Materials Science and Engineering: A. 1998;256(1-2):69-82.

10. Yanran Z, Wang ZR, Weimin C. Numerical simulations for extrusion and ironing and die-angle optimization. Journal of Materials Processing Technology. 1995;55(1):48-52.

11. Shi MF, Gerdeen JC. A Theoretical study of the ironing process in sheet metal forming. Journal of Materials Shaping Technology. 1989;7(4):203-211. DOI: 10.1007/BF02834772
12. Simões VMN. Analysis of the influence of process parameters in the deep drawing of a cylindrical cup. [MSc Thesis]. Coimbra: University of Coimbra; 2012.

13. Adamovic D, Mandic V, Zivkovic M, Gulisija Z, Stefanovic M, Topalovic M, et al. Numerical modeling of ironing process. Journal for Technology of Plasticity. 2013;38(2):109-123.

14. Adamovic D, Mandic V, Jurkovic Z, Grizelj B, Stefanovic M, Marinkovic T, et al. An experimental modelling and numerical FE analysis of steel-strip ironing process. Technical Gazette. 2010;17(4):435-444.

15. Danckert J. Ironing of thin walled cans. CIRP Annals Manufacturing Technology. 2001;50(1):165-168. DOI: 10.1016/ S0007-8506(07)62096-4

16. Indian Standard-IS. IS 1608:2005: Metallic Materials - Tensile Testing at Ambient Temperature. $3^{\text {rd }}$ revision. New Delhi: Bureau of Indian Standards; 2005.

17. Indian Standard-IS. IS 11999:2007: Method for Determination of Plastic Strain Ratio ' $r$ 'for Sheet Metals. $1^{\text {st }}$ revision. New Delhi: Bureau of Indian Standards; 2007.

18. Indian Standard-IS. IS 10175 (Part 1):1993: Mechanical Testing of Metals - Modified Erichsen Cupping Test - Sheet and Strip. $1^{\text {st }}$ revision. New Delhi: Bureau of Indian Standards; 1993.

19. Hosford WF, Caddell RM. Metal Forming - Mechanics and Metallurgy. $3^{\text {rd }}$ ed. Cambridge: Cambridge University Press; 2007. 328 p.

20. Kilfoil LJ. In-plane Plane Strain Testing to Evaluate Formability of Sheet Steels Used in Tubular Products. [MSc Thesis]. Kingston: Queen's University; 2007.

21. Sadagopan S, Urban D. Formability Characterization of a New Generation of Advanced High-Strength Steels. AISI/ DOE Technology Roadmap Program Office. Pittsburgh: U.S. Department of Energy; 2003.

22. Ramsingh RP, Raval HK. Effect of sheet thickness on FLD for AISI - 1008 (HR grade). International Journal of Applied Engineering Research. 2009;4(11):2377-2386.

23. SalehAH,AliAK. Developmenttechnique for deep drawing withoutblank holder to produce circular cup of brass alloy. International Journal of Engineering \& Technology. 2015;4(1):187-195. DOI: $10.14419 /$ ijet.v4i1.3516

24. Shah K, Bhatt D, Panchal T, Panchal D, Dogra B. Influence of the process parameters in deep drawing. International Journal of Emerging Research in Management \& Technology. 2014;3(11):16-22.

25. Foecke T, Gnaeupel-Herold T. Robustness of the sheet metal springback cup test. Metallurgical and Materials Transactions A. 2006;37(12):3503-3510.

26. Danckert J. The Residual Stress Distribution in the Wall of a Deep-Drawn and Ironed Cup Determined Experimentally and by FEM. CIRP Annals - Manufacturing Technology. 1994;43(1):249-252. DOI: 10.1016/S0007-8506(07)62206-9

27. Sunil SU, Pai KB. Investigation of formability of CRCA Steel sheet by Erichsen Cupping Test analysis. IOSR Journal of Mechanical and Civil Engineering. 2014;11(2/1):52-55. DOI: 10.9790/1684-11215255 
28. Kimura T. Formability of TRIP type banitic ferrite steel sheet. Kobelco Technology Review. 2011;30:85-89.

29. Ravi Kumar D. Formability analysis of extra-deep drawing steel. Journal of Materials Processing Technology. 2002;130131:31-41. http://dx.doi.org/10.1016/S0924-0136(02)00789-6

30. Dieter GE Jr. Mechanical metallurgy. $3^{\text {rd }}$ ed. London: McGrawHill Book Co; 1988.
31. Boljanovic V. Metal Shaping Processes: Casting and Molding, Particulate Processing, Deformation Processes, and Metal Removal. New York: Industrial Press; 2009.

32. Tschaetsch H. Metal Forming Practise (Processes-MachinesTools). New York Berlin Heidelberg: Springer-Verlag; 2006. 